\title{
Risk Factors for Mortality among 2009 A/H1N1 Influenza Hospitalizations in Maricopa County, Arizona, April 2009 to March 2010
}

\author{
G. Chowell, ${ }^{1,2}$ A. Ayala, ${ }^{3}$ V. Berisha, ${ }^{3}$ C. Viboud, ${ }^{2}$ and M. Schumacher ${ }^{3}$ \\ ${ }^{1}$ School of Human Evolution and Social Change, Arizona State University, Tempe, AZ 85287, USA \\ ${ }^{2}$ Division of Epidemiology and Population Studies, Fogarty International Center, National Institutes of Health, \\ Bethesda, MD 20892, USA \\ ${ }^{3}$ Office of Epidemiology, Maricopa County Department of Public Health, Phoenix, AZ 85012, USA \\ Correspondence should be addressed to G. Chowell, gchowell@asu.edu \\ Received 14 April 2012; Accepted 28 May 2012 \\ Academic Editor: Hiroshi Nishiura
}

Copyright (C) 2012 G. Chowell et al. This is an open access article distributed under the Creative Commons Attribution License, which permits unrestricted use, distribution, and reproduction in any medium, provided the original work is properly cited.

\begin{abstract}
We analyzed individual-level data on pandemic influenza A/H1N1pdm hospitalizations from the enhanced surveillance system of the Maricopa County Department of Public Health, AZ, USA from April 1st, 2009 to March 31st, 2010. We also assessed the the risk of death among $\mathrm{A} / \mathrm{H} 1 \mathrm{~N} 1$ hospitalizations using multivariate logistic regression. Hospitalization rates were significantly higher among Native Americans (risk ratio $(\mathrm{RR})=6.2$; 95\% CI: 6.15, 6.21), non-Hispanic Black $(\mathrm{RR}=3.84$; 95\% CI: 3.8, 3.9), and Hispanics ( $\mathrm{RR}=2.0 ; 95 \%$ CI: 2.0, 2.01) compared to non-Hispanic Whites. Throughout the spring, 59.2\% of hospitalized patients received antiviral treatment; the proportion of patients treated increased significantly during the fall to $74.4 \%$ (Chi-square test, $P<0.0001)$. In our best-fit logistic model, the adjusted risk of death among $\mathrm{A} / \mathrm{H} 1 \mathrm{~N} 1$ inpatients was significantly higher during the fall wave (August 16, 2009 to March 31, 2010, OR = 3.94; 95\% CI: 1.72, 9.03) compared to the spring wave (April 1, 2009 to August 15, 2009). Moreover, chronic lung disease $(\mathrm{OR}=3.5 ; 95 \% \mathrm{CI}: 1.7,7.4)$, cancer within the last 12 months $(\mathrm{OR}=4.3 ; 95 \% \mathrm{CI}: 1.3$, 14.8), immuno-suppression ( $\mathrm{OR}=4.0 ; 95 \% \mathrm{CI}: 1.84,8.9)$, and admission delays ( $\mathrm{OR}=4.6$; $95 \% \mathrm{CI}: 2.2,9.5)$ were significantly associated with an increased the risk of death among A/H1N1 inpatients.
\end{abstract}

\section{Introduction}

The first cases of the $2009 \mathrm{~A} / \mathrm{H} 1 \mathrm{~N} 1$ influenza pandemic were confirmed in California on April 21, and in Mexico on April 23, 2009 [1]. In the state of Arizona, the first case of novel $\mathrm{A} / \mathrm{H} 1 \mathrm{~N} 1$ influenza was confirmed on April 29 and the first death associated with the novel A/H1N1 virus was identified on May 14th with a date of illness onset on April 28, 2009. Preliminary estimates of the 2009 A/H1N1 influenza pandemic burden indicate that between 7,500 and 44,100 deaths can be attributed to the novel A/H1N1 influenza virus in the United States (US) from May through December, 2009 [2].

In Maricopa County (MC), AZ the first wave of novel A/H1N1 started in late April 2009, closely following the first detection of the virus in California. A second wave of illness began around August 2009 and peaked in October 2009. At the beginning of the first wave, the Department of Public Health (MCDPH) Office of Epidemiology put in place an enhanced surveillance system to identify inpatients diagnosed with 2009 A/H1N1 influenza across all hospitals in the county. The rapid increase of novel A/H1N1 influenza cases at an unusual time of the year prompted the MCDPH to enhance surveillance activities, increase communication with local healthcare providers, establish collaborations with state and federal public health agencies, and disseminate continuous updates on the pandemic status to the community.

Analyzing the impact of the $2009 \mathrm{~A} / \mathrm{H} 1 \mathrm{~N} 1$ influenza in MC is of particular interest as $39 \%$ of the population is composed of Hispanics, non-Hispanic Blacks, Native Americans, and Asians. Assessing differences in hospitalization and death rates according to ethnic/race groups could inform 
preventive and control efforts by helping identify vulnerable populations at increased risk of severe disease outcomes. Thus, we analyzed individual-level data on hospitalized patients with laboratory-confirmed $\mathrm{A} / \mathrm{H} 1 \mathrm{~N} 1 \mathrm{pdm}$ influenza complied by the enhanced surveillance system put in place by MCDPH from April 1, 2009 to March 31, 2010. This type of study could shed light on the identification of vulnerable subpopulations at increased risk of severe disease outcomes and inform prevention guidelines for epidemic and pandemic influenza.

\section{Materials and Methods}

2.1. The Study Location: Maricopa County. Maricopa County is the third most populous local public health jurisdiction in the US, behind New York City and Los Angeles County, with a population of 3.8 million comprising $60 \%$ percent of Arizona state's population.

2.2. Epidemiological and Population Data. Detailed data on hospitalized patients with $\mathrm{A} / \mathrm{H} 1 \mathrm{~N} 1$ influenza was available from an enhanced epidemiological surveillance system that was put in place to keep track of the 2009 influenza pandemic by the MCDPH Office of Epidemiology. Enhanced surveillance was conducted at all hospitals in MC to detect patients hospitalized with confirmed $2009 \mathrm{~A} / \mathrm{H} 1 \mathrm{~N} 1$ infection and to detect A/H1N1 deaths. MCDPH requested that all Maricopa County hospitals consider for testing patients presenting with fever $\left(>37.8^{\circ} \mathrm{C}\right.$ or $\left.100^{\circ} \mathrm{F}\right)$ and respiratory symptoms (including cough and sore throat) or sepsis-like syndrome. Medical records and laboratory results were reviewed as cases were reported to the surveillance system. Information collected on a standard form included demographics (age, gender, ethnicity/race), dates of onset of symptoms and hospitalization, underlying risk factor data (asthma, chronic lung disease, cardiac disease, obesity, metabolic disease, diabetes, kidney disease, cancer during the last 12 months, immunosuppression, and neurological disease), hospitalization duration, and whether the patient was treated with neuraminidase inhibitors. Immunosuppressive conditions included patients undergoing chemotherapy, chronic corticosteroid therapy, immunosuppressant therapy, or patients diagnosed with DiGeorge Syndrome, Wiskott-Aldrich Syndrome, HIV/AIDS, hypogammaglobulinemia, and organ transplant recipients. We defined the admission delay as the time elapsed from symptoms onset to hospitalization admission. We stratified admission delay into two groups $\leq 2$ and $>2$ days based on treatment recommendations to initiate antiviral medication within $48 \mathrm{~h}$ of disease onset. Antiviral treatment with neuraminidase inhibitors (Oseltamivir and Zanamivir) was considered for all hospitalized patients with suspected A/H1N1 infection. In addition, MCDPH developed a comprehensive surveillance methodology to identify A/H1N1 deaths. This effort included close collaboration with the MC Office of the Medical Examiner (ME) to investigate all suspect A/H1N1 deaths and with the Office of Vital Statistics by cross-referencing death certificates with cases reported to MCDPH.
Our analysis is focused on patients diagnosed with 2009 $\mathrm{A} / \mathrm{H} 1 \mathrm{~N} 1$ influenza who were hospitalized in public and private hospitals in MC from April 2009 to March 2010 and for which a standard investigation form was completed. Laboratory diagnosis of patients was performed by RTPCR or viral culture. Hospitalizations for which a form was not completed were excluded from analysis. Based on the date of notification, the first pandemic wave (spring wave) comprised the period from April 1, 2009 to August 15, 2009 while the fall pandemic wave was from August 16, 2009 to March 31, 2010 and coincided with the return of students from summer vacations.

We also calculated standardized hospitalization rates based on population estimates according to age and race groups for MC in 2009 [3].

2.3. Hospitalized Case Fatality Ratios. The hospitalized case fatality ratio (hCFR) measures the severity of an infectious disease and is defined as the proportion of deaths among all hospitalized cases. Here, we estimated the case fatality ratio among novel $\mathrm{A} / \mathrm{H} 1 \mathrm{~N} 1$ hospitalizations $(\mathrm{HCFR}=\mathrm{H} 1 \mathrm{~N} 1$ inpatient deaths/H1N1 inpatients). We analyzed the hCFR according to administration of neuraminidase inhibitor, age groups, ethnic/race groups, and pandemic waves.

2.4. Modeling Risk of Death among A/H1N1 Influenza Hospitalizations. We used multivariate logistic regression models to assess the risk of $\mathrm{A} / \mathrm{H} 1 \mathrm{~N} 1$ death among hospitalized patients with $\mathrm{A} / \mathrm{H} 1 \mathrm{~N} 1$ influenza after adjustment for age, gender, ethnicity/race, pandemic wave, admission delay, antiviral treatment, and underlying medical conditions. In particular, we sought to investigate the effect of ethnicity/ race among Hispanics, non-Hispanic Whites, non-Hispanic Blacks, Asians, and Native Americans on the risk of death among A/H1N1 inpatients. We also quantified the interaction between antiviral treatment and admission delay to account for the fact that patients admitted earlier in their disease course had a higher probability of receiving antiviral treatment. We analyzed fully adjusted and simplified logistic regression models generated via stepwise backward elimination. We measured the strength of model predictors using odds ratios (95\% CI) and $P$ values. Records with missing data were excluded from the analysis.

This study was granted exempt IRB status from Arizona State University (IRB Protocol number: 1205007823). All investigations were part of public health practice; all individual data were kept confidential, and patients could not be identified. Statistical analyses were performed using SPSS 20.0 .

\section{Results}

The characteristics of $\mathrm{A} / \mathrm{H} 1 \mathrm{~N} 1$ influenza hospitalized patients and deaths with complete case investigations by pandemic wave are shown in Table 1, and the temporal profile of hospitalizations and deaths is illustrated in Figure 1. Of the 609 patients investigated by the MCDPH between April 2009 and March 2010, there were 532 hospitalized patients who 


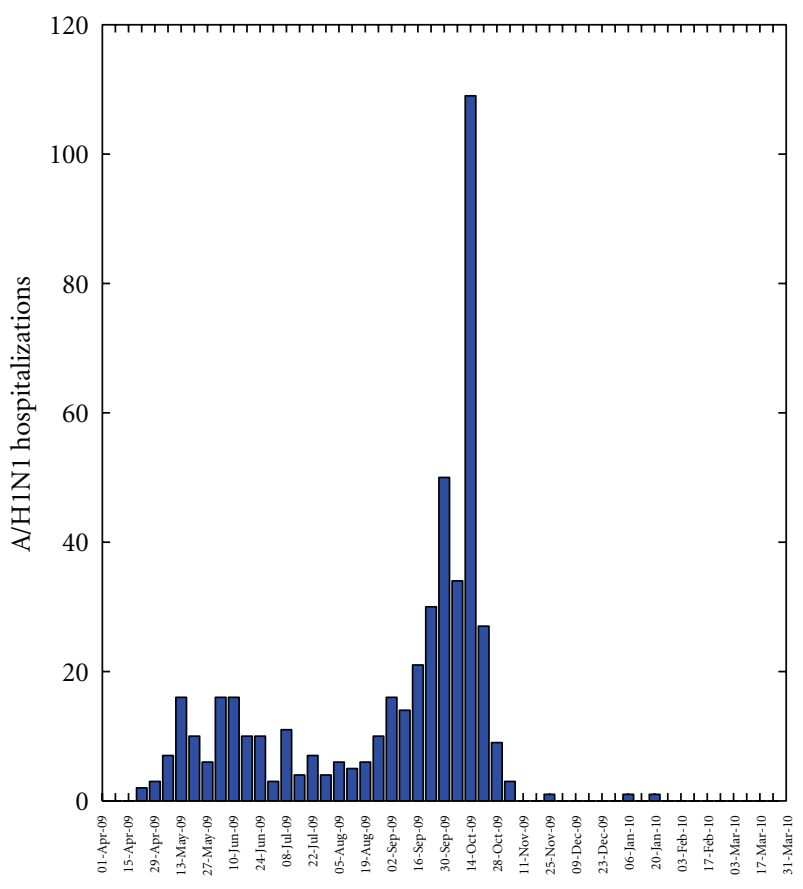

(a)

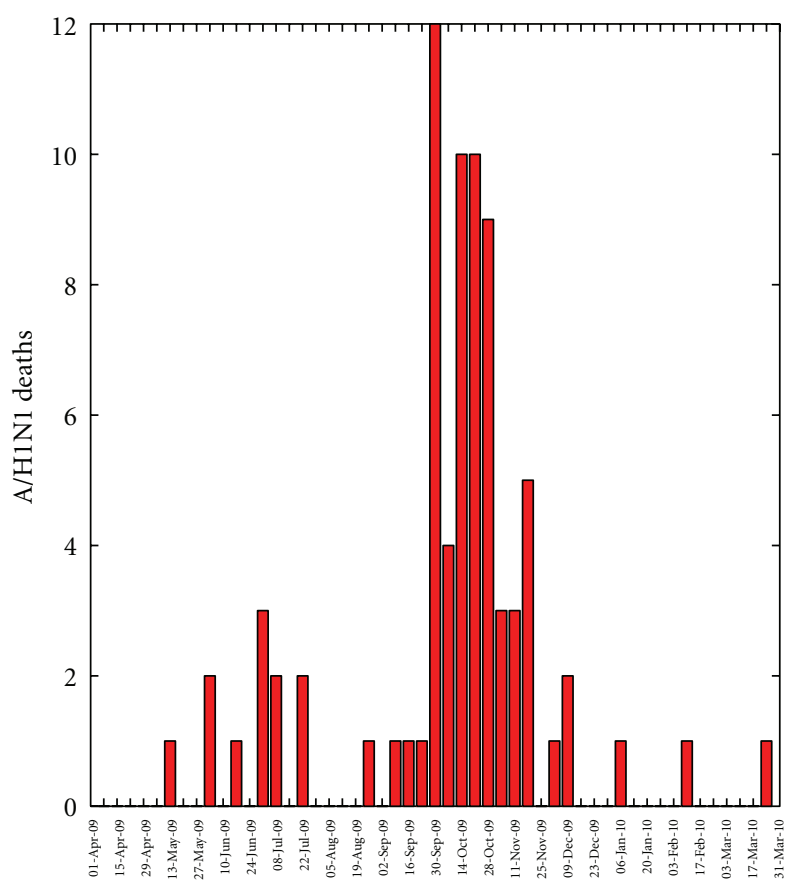

(b)

FIGURE 1: Weekly number of new A/H1N1 influenza inpatients and deaths by date of notification to Maricopa County from April 1, 2009 to March 31, 2010.

TABle 1: Characteristics of A/H1N1 influenza hospitalizations and deaths by pandemic wave, Maricopa County, April 1, 2009 to March 31, 2010.

\begin{tabular}{|c|c|c|c|c|}
\hline \multirow{2}{*}{ Variable } & \multirow{2}{*}{ Total } & \multicolumn{2}{|c|}{ Pandemic wave } & \multirow{2}{*}{$P$ value $^{\mathrm{a}}$ (degrees of freedom) } \\
\hline & & Spring & Fall & \\
\hline \multicolumn{5}{|l|}{ Age (years) } \\
\hline$<18$ & $246 / 546(45.1)$ & $62 / 144(43.1)$ & $184 / 402(45.8)$ & \multirow{3}{*}{$0.045(2)$} \\
\hline $18-49$ & $183 / 546(33.5)$ & $41 / 144(26.9)$ & $142 / 402(35.3)$ & \\
\hline$\geq 50$ & $117 / 546(21.4)$ & $41 / 144(28.4)$ & $76 / 402(18.9)$ & \\
\hline \multicolumn{5}{|l|}{ Race/ethnicity } \\
\hline Hispanics & $206 / 546(37.7)$ & $60 / 144(41.7)$ & $146 / 402(36.3)$ & \multirow{6}{*}{$0.54(5)$} \\
\hline Whites, non-Hispanic & $207 / 546(37.9)$ & $52 / 144(36.1)$ & $155 / 402(38.6)$ & \\
\hline Black, non-Hispanic & $62 / 546(11.4)$ & $13 / 144(9.0)$ & $49 / 402(12.2)$ & \\
\hline Native American & $34 / 546(6.2)$ & 9/144 (6.2) & $25402(6.2)$ & \\
\hline Asian & $5 / 546(0.9)$ & $0 / 144(0.0)$ & $5 / 402(1.2)$ & \\
\hline Other/unknown & $32 / 546(5.9)$ & $10 / 144(6.9)$ & $22 / 402(5.5)$ & \\
\hline \multicolumn{5}{|l|}{ Gender } \\
\hline Female & $303 / 546(55.5)$ & $80 / 144(55.6)$ & $223 / 402(55.5)$ & \multirow{2}{*}{$0.99(1)$} \\
\hline Male & $243 / 546(44.5)$ & $64 / 144(44.4)$ & $179 / 402(44.5)$ & \\
\hline \multicolumn{5}{|l|}{ Patients according to severity } \\
\hline ICU & $153 / 519(29.5)$ & $41 / 140(29.3)$ & $112 / 379(29.6)$ & $0.95(1)$ \\
\hline Mechanical ventilation & $106 / 522(20.3)$ & 28/144 (19.4) & $78 / 378(20.6)$ & $0.76(1)$ \\
\hline Deaths & $77 / 546(14.1)$ & $11 / 144(7.6)$ & $66 / 402(16.4)$ & $0.009(1)$ \\
\hline
\end{tabular}

Wave 1 (spring) refers to April 1 through August 15, 2009; fall wave refers to August 16, 2009 through March 31, 2010. Data are percentages of cases unless otherwise specified.

${ }^{a}$ Determined by the Chi-square test statistic. $P$ values for age and race/ethnicity obtained from group wise comparisons, while $P$ values for gender and severity comparisons correspond to each category. 
TABLE 2: Rates of antiviral administration (mean and 95\% confidence intervals) among A/H1N1 influenza inpatients by pandemic wave, Maricopa County, April 1, 2009 to March 31, 2010.

\begin{tabular}{|c|c|c|c|c|}
\hline \multirow{2}{*}{ Variable } & \multirow{2}{*}{ Total } & \multicolumn{2}{|c|}{ Pandemic wave } & \multirow{2}{*}{$P$ value ${ }^{\mathrm{a}}$} \\
\hline & & Spring & Fall & \\
\hline Number of patients that received antivirals ( $\%$ of total A/H1N1 cases) & $361 / 500(72.2)$ & $84 / 142(59.2)$ & $277 / 358(74.4)$ & $<0.0001$ \\
\hline \multicolumn{5}{|l|}{ Race/ethnicity } \\
\hline Hispanics & $128 / 190(67.4)$ & $29 / 60(48.3)$ & $99 / 130(76.2)$ & $<0.0001$ \\
\hline Whites, non-Hispanic & $136 / 186(73.1)$ & $31 / 51(60.8)$ & $105 / 135(77.8)$ & 0.02 \\
\hline Black, non-Hispanic & $46 / 59(78.0)$ & $12 / 13(92.3)$ & $34 / 46(73.9)$ & 0.16 \\
\hline Native American & $24 / 30(80.0)$ & $6 / 8(75.0)$ & $18 / 22(81.8)$ & 0.68 \\
\hline Asian & $4 / 4(100)$ & $0 / 0(0.0)$ & $4 / 4(100.0)$ & N/A \\
\hline \multicolumn{5}{|l|}{ Gender } \\
\hline Female & $206 / 280(73.6)$ & $49 / 79(62.0)$ & $157 / 201(78.1)$ & 0.006 \\
\hline Male & $155 / 220(70.5)$ & $35 / 63(55.6)$ & $120 / 157(76.4)$ & 0.002 \\
\hline \multicolumn{5}{|l|}{ Age (years) } \\
\hline$<18$ & $161 / 231(69.7)$ & $31 / 61(50.8)$ & $130 / 170(76.5)$ & $<0.0001$ \\
\hline $18-49$ & $122 / 162(75.3)$ & $22 / 40(55.0)$ & $100 / 122(82.0)$ & 0.001 \\
\hline$\geq 50$ & $78 / 107(72.9)$ & $31 / 41(75.6)$ & $47 / 66(71.2)$ & 0.62 \\
\hline \multicolumn{5}{|l|}{ Patients according to severity } \\
\hline ICU & $111 / 150(74.0)$ & $23 / 41(56.1)$ & $88 / 109(80.7)$ & 0.002 \\
\hline Mechanical ventilation & $73 / 105(69.5)$ & $13 / 28(46.4)$ & $60 / 77$ (77.9) & 0.002 \\
\hline Deaths & $43 / 63(68.3)$ & $5 / 11(45.5)$ & $38 / 52(73.1)$ & 0.074 \\
\hline
\end{tabular}

Wave 1 (spring) refers to April 1 through August 15, 2009; fall wave refers to August 16, 2009 through March 31, 2010. Data are percentages of cases unless otherwise specified.

${ }^{a}$ Determined by the Chi-square test statistic. $P$ values show the univariate comparisons of proportions between spring and fall waves.

recovered, 65 inpatient deaths, and 12 at-home deaths. The number of laboratory-confirmed A/H1N1 hospitalizations (deaths) reported in the spring and fall waves were 144 (11) and 388 (66), respectively. The median age among A/H1N1 hospitalizations was 21 years (range: $0-96 \mathrm{y}$ ), and the median age among $\mathrm{A} / \mathrm{H} 1 \mathrm{~N} 1$ inpatient deaths was $46 \mathrm{y}$ (range: $0-80 \mathrm{y}$ ). The fraction of $\mathrm{A} / \mathrm{H} 1 \mathrm{~N} 1$ hospitalizations among young persons $(18-49 \mathrm{y})$ increased from $26.9 \%$ to $35.3 \%$ and decreased from $28.4 \%$ to $18.9 \%$ among seniors $(\geq 50 y)$ from the spring to the fall wave.

Hospitalization rates were significantly higher among Native Americans (risk ratio $(\mathrm{RR})=6.2 ; 95 \% \mathrm{CI}$ : 6.15, 6.21), non-Hispanic Black ( $\mathrm{RR}=3.84$; 95\% CI: 3.8, 3.9), and Hispanics $(\mathrm{RR}=2.0$; 95\% CI: 2.0, 2.01) compared to non-Hispanic Whites. The median age among A/H1N1 hospitalized Native Americans was $21 \mathrm{y}($ range $=0-73 \mathrm{y})$, among hospitalized non-Hispanic Blacks was $15 \mathrm{y}$ (range = 0-82 y), among Hispanics was $14 \mathrm{y}$ (range $=0-81 \mathrm{y}$ ), and among hospitalized non-Hispanic Whites was $35 \mathrm{y}$ (range $=$ 0-96 y). Slightly higher proportions of females than males (55\% males, $45 \%$ females) were affected both in the spring and fall pandemic waves (Chi-square test, $P=0.99$, Table 1). Similarly, the proportions of hospitalizations by ethnicity/race groups were not significantly different in the spring versus the fall pandemic waves (Chi-square test, $P=$ 0.54, Table 1).

3.1. Temporal Patterns of Admission Delays and Neuraminidase Inhibitor Administration. The average admission delay was slightly but significantly higher during the spring wave compared to the fall wave ( $2.9 \mathrm{~d}$ versus $2.4 \mathrm{~d}$, Wilcoxon test, $P<0.001)$. A total of $361(72.2 \%)$ hospitalized patients were treated with antivirals (Table 2). There was a significant change in the pattern of antiviral administration between the spring and fall pandemic waves of 2009. In particular, antiviral administration rates were at $59.2 \%$ among hospitalized patients throughout the spring (April 1 to August $15,2009)$ and increased significantly later in the pandemic to $74.4 \%$ during the fall pandemic wave (Table 2, Chisquare test, $P<0.0001)$. Moreover, antiviral treatment rates were significantly lower during the spring pandemic wave compared to the fall wave for Hispanics ( $48.3 \%$ versus $76.2 \%$, Chi-square test, $P<0.0001$ ) and non-Hispanic whites (61\% versus $77.8 \%$, Chi-square test, $P=0.02)$. Antiviral treatment for children and young adults increased during the fall pandemic wave as shown in Table 2. No differences by gender, age, and ethnicity/race in the cumulative antiviral administration rates were observed $(P>0.29)$.

3.2. Hospitalized Case Fatality Ratios. We found significant temporal differences in the hCFR based on hospitalized patients (Table 3). The overall hCFR based on hospitalized patients was estimated at $12.2 \%$. The hCFR was higher during the fall pandemic wave compared to the spring wave despite the increased antiviral administration rates during the fall $(7.6 \%$ versus $13.9 \%$, Chi-square test, $P=0.05)$. Moreover, hCFR among hospitalized patients increased as age group gets older (Chi-square test, $P<0.0001$ ) but was 
TABle 3: Unadjusted case fatality ratios among A/H1N1 influenza inpatients by pandemic wave, Maricopa County, April 1, 2009 through March 31, 2010.

\begin{tabular}{|c|c|c|c|c|}
\hline \multirow{2}{*}{ Variable } & \multirow{2}{*}{ Overall hospitalized case fatality ratio } & \multicolumn{2}{|c|}{ Pandemic wave } & \multirow{2}{*}{$P$ value } \\
\hline & & Spring & Fall & \\
\hline Total A/H1N1 deaths ( $\%$ of total A/H1N1 cases) & $65 / 532(12.2)$ & $11 / 144(7.6)$ & $54 / 388(13.9)$ & 0.049 \\
\hline \multicolumn{5}{|l|}{ Race/ethnicity } \\
\hline Hispanics & $18 / 202(8.9)$ & $5 / 60(8.3)$ & $13 / 142(9.2)$ & 0.85 \\
\hline Whites, non-Hispanic & $36 / 197(18.3)$ & $4 / 52(7.7)$ & $32 / 145(22.1)$ & 0.021 \\
\hline Black, non-Hispanic & $5 / 62(8.1)$ & $2 / 13(15.4)$ & $3 / 49(6.1)$ & 0.31 \\
\hline Native American & $4 / 34(11.8)$ & $0 / 9(0.0)$ & $4 / 25(16.0)$ & 0.20 \\
\hline Asian & $2 / 5(40.0)$ & $0 / 0(0.0)$ & $2 / 5(40.0)$ & N/A \\
\hline \multicolumn{5}{|l|}{ Gender } \\
\hline Female & $36 / 297(12.1)$ & $5 / 80(6.2)$ & $31 / 217(14.3)$ & 0.060 \\
\hline Male & $29 / 235(12.3)$ & $6 / 64(9.4)$ & $23 / 171(13.5)$ & 0.40 \\
\hline \multicolumn{5}{|l|}{ Age (years) } \\
\hline$<18$ & $11 / 243(4.5)$ & $2 / 62(3.2)$ & $9 / 181(5.0)$ & 0.57 \\
\hline $18-49$ & $24 / 175(13.7)$ & $3 / 41(7.3)$ & $21 / 134(15.7)$ & 0.17 \\
\hline$\geq 50$ & $30 / 114(26.3)$ & $6 / 41(14.6)$ & $24 / 73(32.9)$ & 0.034 \\
\hline
\end{tabular}

Wave 1 (spring) refers to April 1, 2009 through August 15, 2009; fall wave refers to August 16, 2009 through March 31, 2010. Data are percentages of cases unless otherwise specified.

${ }^{a}$ Determined by the Chi-square test statistic. $P$ values show the univariate comparisons of proportions between spring and fall waves.

TABLE 4: Frequency of risk factors for A/H1N1 inpatients, Maricopa County, April 1, 2009 to March 31, 2010.

\begin{tabular}{|c|c|c|c|}
\hline Risk factors & $\mathrm{A} / \mathrm{H} 1 \mathrm{~N} 1$ inpatients & A/H1N1 fatal & $\begin{array}{c}\text { A/H1N1 hospitalization versus } \\
\text { A/H1N1 death odds ratio }(95 \% \mathrm{CI})^{\mathrm{a}}\end{array}$ \\
\hline Asthma & $127 / 449(28.3)$ & $16 / 64(25.0)$ & $0.73(0.32,1.7)$ \\
\hline Chronic lung disease & $101 / 447(22.6)$ & $36 / 65(55.4)$ & $3.3(1.5,7.5)$ \\
\hline Cardiac disease & $80 / 419(19.1)$ & $23 / 65(35.4)$ & $1.33(0.54,3.3)$ \\
\hline Metabolic disease & $71 / 450(15.8)$ & $21 / 65(32.3)$ & $3.35(0.55,20.5)$ \\
\hline Diabetes & $61 / 451(13.5)$ & $19 / 65(29.2)$ & $0.3(0.04,2.11)$ \\
\hline Kidney disease & $34 / 453(7.5)$ & $11 / 64(17.2)$ & $0.96(0.31,3.01)$ \\
\hline Cancer last 12 months & $16 / 455(3.5)$ & $13 / 65(20.0)$ & $3.8(1.01,14.3)$ \\
\hline Immune suppression & $93 / 458(20.3)$ & $35 / 65(53.8)$ & $4.6(2.0,10.6)$ \\
\hline Neurological disease & $80 / 455(17.6)$ & $20 / 65(30.8)$ & $1.7(0.72,4.1)$ \\
\hline
\end{tabular}

${ }^{a}$ Risk of death among A/H1N1 inpatients adjusted by age, gender, ethnicity/race, pandemic wave, and antiviral treatment.

not significantly different by gender (Chi-square test, $P=$ 0.94). Furthermore, the hCFR estimates increased among non-Hispanic Whites from the spring to the fall pandemic wave $(7.7 \%$ versus $22.1 \%$, Chi-square test, $P=0.02)$ and increased twofold among persons $\geq 50 \mathrm{y}$ from the spring to the fall pandemic wave $(14.6 \%$ versus $32.9 \%$, Chi-square test, $P=0.03$ ). The hCFR was significantly higher among inpatients with admission delays $>2$ days compared to inpatients with shorter admission delays $(21.2 \%$ versus $5.9 \%$, Chi-square test, $P<0.0001$ ).

3.3. Multivariate Logistic Regression Analysis. Among inpatients with confirmed $\mathrm{A} / \mathrm{H} 1 \mathrm{~N} 1$, one or more comorbidities were present in $68.3 \%$ of $\mathrm{A} / \mathrm{H} 1 \mathrm{~N} 1$ inpatients under 18 years of age and in $77.2 \%$ of inpatients 18 years and older. The most common comorbidities among $\mathrm{A} / \mathrm{H} 1 \mathrm{~N} 1$ inpatient deaths were chronic lung disease (55.4\%) and immune suppression $(53.8 \%)$ (Table 4$)$.
In a fully adjusted multivariate logistic regression analysis of the risk factors for dying from $\mathrm{A} / \mathrm{H} 1 \mathrm{~N} 1$ influenza hospitalization, we found Asian inpatients to be at an increased risk of death $(\mathrm{OR}=24.1$ (95\% CI: 2.5, 234)) after adjusting for all other factors. We also found chronic lung disease $(\mathrm{OR}=$ 3.3 (95\% CI: 1.5, 7.5)), cancer within the last 12 months (3.8 (95\% CI: 1.01, 14.3)), immunosuppression $(\mathrm{OR}=4.6$ (95\% CI: 2.0, 10.6)), fall pandemic wave (OR $=4.5$ (95\% CI: $1.82,11.2)$ ), and admission delay ( $\mathrm{OR}=11.5$ (95\% CI: 2.4 , $55.2)$ ) to be the strongest predictors of death among A/H1N1 inpatients with full adjustment for all other covariates. Of note, a total of 101 inpatient records (19\%) had to be excluded for fully adjusted multivariate logistic regression analyses due to missing data.

A simplified model obtained via backward elimination procedure included age groups, ethnicity/race groups where Asian inpatients had a higher risk of death, pandemic wave, chronic lung disease, cancer within the last 12 months, 
immunosuppression, and admission delay as shown in Table 5. Antiviral treatment was dropped from the final model as it lacked statistical significance. The model fit to the data was not rejected according to the Hosmer-Lemeshow test statistic $(P=0.48)$.

\section{Discussion}

Although a number of studies have shed light on the risk factors associated with severe outcomes of 2009 A/H1N1 influenza infections in different populations (e.g., [4-8]), analyses of severity outcomes according to ethnicity/race groups are scarce $[9,10]$. Here, we have analyzed 532 $\mathrm{A} / \mathrm{H} 1 \mathrm{~N} 1$ hospitalizations and $77 \mathrm{~A} / \mathrm{H} 1 \mathrm{~N} 1$ deaths in Maricopa County as collected by a prospective surveillance system put in place by the Maricopa County Department of Public Health during April 2009 to March 2010. Our data comprises two main pandemic waves in the spring and fall in Maricopa County, which were associated with high hospitalization rates particularly among racial and ethnic minority groups (Native Americans, non-Hispanic Blacks, and Hispanics). Moreover, we found Asian inpatients to be at a higher risk of death compared to other ethnic/race groups after adjustment for age, gender, antiviral treatment, admission delays, and comorbidities. Our findings also suggest a higher risk of death among $\mathrm{A} / \mathrm{H} 1 \mathrm{~N} 1$ hospitalizations during the major fall pandemic wave after adjusting for factors other than intrinsic changes in virus characteristics. In particular, our results underscore the impact of admission delays and underlying medical conditions particularly immune suppression, chronic lung disease, and cancer within the last 12 months in increasing the risk of death following A/H1N1 hospitalization after adjusting for other covariates.

We found risk of death among A/H1N1 inpatients to be significantly higher during the fall pandemic wave compared to the spring pandemic wave after adjustment for demographic, antiviral treatment, and comorbidities. We note that this result is in contrast with an analysis of the risk of death among hospitalized cases during the summer and fall 2009 A/H1N1 pandemic waves in England [11]. Other factors could have contributed to this result, for example, hospitalization of $\mathrm{A} / \mathrm{H} 1 \mathrm{~N} 1$ cases becoming more selective as the pandemic progressed-that is, only the most severe cases were hospitalized during later months which is in line with the increase in antiviral treatment during the fall wave (Table 2). Overall rates of antiviral administration among hospitalized patients were high during the entire pandemic period in Maricopa County during the 2009 pandemic and are in close agreement with US national estimates (50-82\%) $[7,12,13]$.

Hospitalization rates among Native Americans, nonHispanic Blacks, and Hispanics were 2-6 times higher than those observed among non-Hispanic Whites, which is in agreement with an analysis of hospitalized patients during the 2009 A/H1N1 influenza pandemic in Wisconsin, New Mexico, and the US overall [9, 14, 15]. While Asians experienced the lowest $\mathrm{A} / \mathrm{H} 1 \mathrm{~N} 1$ hospitalization rates among ethnic/race groups, this group showed a statistically significant increased risk of death in the hospital
TABLE 5: Final logistic regression model of risk of death based on $\mathrm{A} / \mathrm{H} 1 \mathrm{~N} 1$ hospitalizations and obtained via backward elimination procedure.

\begin{tabular}{lcc}
\hline Risk factors & $P$ value & OR $(95 \% \text { CI })^{\mathrm{a}}$ \\
\hline $\begin{array}{l}\text { Age groups } \\
<18 \mathrm{y}\end{array}$ & 0.004 & $0.27(0.11,0.66)$ \\
$18-49 \mathrm{y}$ & 0.83 & $1.1(0.47,2.6)$ \\
$\quad \geq 50 \mathrm{y}$ & Ref value & 1 \\
Ethnicity/race & & \\
$\quad$ Unknown & 0.99 & 0 \\
Hispanics & 0.24 & $1.65(0.72,3.8)$ \\
Native American & 0.75 & $1.24(0.33,4.7)$ \\
$\quad$ Non-Hispanic black & 0.54 & $0.67(0.20,2.4)$ \\
$\quad$ Asian & 0.008 & $23.3(2.3,238.3)$ \\
$\quad$ Non-Hispanic white & Ref value & 1 \\
Pandemic wave & & \\
Fall wave & 0.001 & $3.94(1.72,9.03)$ \\
Chronic lung disease & 0.001 & $3.5(1.66,7.4)$ \\
Cancer within last 12 months & 0.02 & $4.3(1.3,14.8)$ \\
Immune suppression & 0.001 & $4.0(1.84,8.9)$ \\
Admission delay & $<0.001$ & $4.6(2.2,9.5)$ \\
\hline
\end{tabular}

${ }^{a}$ Risk of death among A/H1N1 inpatients. The corresponding HosmerLemeshow test statistic for model fit $(P=0.48)$ and the Cox and Snell $R^{2}=$ 0.22 .

$(\mathrm{OR}=23.3)$ after adjustment for other covariates. We note that the corresponding odds ratio for the risk of death among A/H1N1 Asian inpatients lacks precision (wide confidence interval) due to the small number of Asian cases in our sample. Lack of surveillance data, particularly among Asian Americans and Native Hawaiians/Pacific Islanders, has been previously noted, and a smaller influenza burden among Asian Americans and Native Hawaiians/Pacific Islanders has been suggested [15]. Our unexpected findings could be explained as a result of differences in health-care seeking behavior among ethnic/race groups where only the most severe A/H1N1-positive Asian infected cases sought health care services during the pandemic period.

We note that in our sample $68.3 \%$ of hospitalized patients $<18$ years of age with $\mathrm{A} / \mathrm{H} 1 \mathrm{~N} 1$ infection had one or more comorbidities, which is substantially higher to that reported among $\mathrm{A} / \mathrm{H} 1 \mathrm{~N} 1$ inpatients in Wisconsin (25\%) during the $2009 \mathrm{~A} / \mathrm{H} 1 \mathrm{~N} 1$ influenza pandemic [9]. In line with previous studies [16-19], immunosuppression $(\mathrm{OR}=4.5$ (95\% CI: $2.1,9.7)$ ) was a significant risk factor of mortality among $\mathrm{A} / \mathrm{H} 1 \mathrm{~N} 1$ inpatients in an adjusted multivariate logistic regression analysis. Similarly, chronic lung disease $(\mathrm{OR}=$ 3.5) and cancer within the last 12 months $(\mathrm{OR}=4.3)$ were associated with an increase risk of death among $\mathrm{A} / \mathrm{H} 1 \mathrm{~N} 1$ inpatients, which is also in agreement with previous studies $[15,17,20]$.

We did not find diabetes to be significantly associated with risk of death among $\mathrm{A} / \mathrm{H} 1 \mathrm{~N} 1$ inpatients. In contrast, previous studies have identified diabetes to be significantly associated with death from pandemic A/H1N1 influenza $[16,21]$. Obesity information in our data was missing in over 
$30 \%$ of inpatient records, and, hence, it was excluded from the multivariate logistic regression analysis. Several studies have supported a link between obesity and increased risk of death with seasonal influenza [22] and 2009 pandemic A/H1N1 influenza [8, 21, 23-27].

Treatment with antivirals was not found to be significantly associated with a reduced risk of death after adjustment for other covariates. Nevertheless, data on antiviral treatment was obtained retrospectively by examining medical records, but the date of the start of treatment relative to the onset of symptoms was not available for analysis. By contrast, delay in admission $>2$ days was significantly associated with an increased risk of death $(\mathrm{OR}=4.6)$ in line with previous studies [5, 28-36].

Our study has several strengths and limitations worth noting. We used detailed hospitalization data from an enhanced surveillance system that covered all hospitals in the county. However, we included in our analysis only those hospitalizations for which an investigation was conducted (about $50 \%$ of all A/H1N1 influenza hospitalizations). Our individual-level clinical data allowed us to assess the effect of ethnic/race groups, age, gender, and underlying comorbidities on the risk of death among A/H1N1 influenza inpatients in a multivariate logistic regression framework. Moreover, risk factor data were recorded in most medical records with $2-4 \%$ of inpatient records missing comorbidities except for cardiac disease, which was missing $9.3 \%$ of records, and obesity was not included in our analysis as it was missing in $>30 \%$ inpatient records.

In summary, we found that Native Americans, nonHispanic Blacks, and Hispanics experienced significantly higher $\mathrm{A} / \mathrm{H} 1 \mathrm{~N} 1$ hospitalization rates than non-Hispanic Whites, and the risk of death among $\mathrm{A} / \mathrm{H} 1 \mathrm{~N} 1$ inpatients was statistically higher among Asian inpatients compared to other racial and ethnic groups after appropriate adjustment for demographic and medical factors. More studies are needed to better understand potential differential mortality impact of A/H1N1-related hospitalizations among different ethnicity/race groups. Our findings also underscore the role of admission delays, immunosuppression, cancer within the last 12 months, and chronic lung disease on mortality associated with $2009 \mathrm{~A} / \mathrm{H} 1 \mathrm{~N} 1$ pandemic influenza. Providers should recommend influenza vaccination to patients with these medical conditions. In addition, when these high-risk patients do become hospitalized, providers should be aware of their increased risk of fatal outcomes.

\section{Acknowledgments}

The authors would like to thank their partners at the Maricopa County Office of the Medical Examiner, the Arizona Department of Health Services, the Centers for Disease Control and Prevention, infection preventionists at Maricopa County local hospitals, as well as all MCDPH staff who helped with case reporting and case investigation of Novel H1N1-related cases. They thank Liva Nohre for providing statistical analyses input and Amy Prestanski for facilitating 2009 population data for Maricopa County. This research was conducted in the context of the MISMS
(Multinational Influenza Seasonal Mortality Study), an ongoing international collaborative effort to understand influenza epidemiological and evolutionary patterns, led by the Fogarty International Center, National Institutes of Health (http://www.origem.info/misms/index.php). The MISMS study is funded by the International Influenza Unit, Office of Global Health Affairs, Department of Health and Human Services.

\section{Conflict of Interests}

The authors declare no competing interests relevant to this paper.

\section{References}

[1] G. Chowell, S. M. Bertozzi, M. A. Colchero et al., "Severe respiratory disease concurrent with the circulation of H1N1 influenza," New England Journal of Medicine, vol. 361, no. 7, pp. 674-679, 2009.

[2] C. Viboud, M. Miller, D. Olson, M. Osterholm, and L. Simonsen, "Preliminary Estimates of Mortality and Years of Life Lost Associated with the 2009 A/H1N1 Pandemic in the US and Comparison with Past Influenza Seasons," PLoS Currents, RRN1153, 2010.

[3] United States Census, Population Estimates Division. 20002010 Intercensal Population Estimates.

[4] J. K. Louie, M. Acosta, K. Winter et al., "Factors associated with death or hospitalization due to pandemic 2009 influenza $\mathrm{A}(\mathrm{H} 1 \mathrm{~N} 1)$ infection in California," Journal of the American Medical Association, vol. 302, no. 17, pp. 1896-1902, 2009.

[5] G. Domínguez-Cherit, S. E. Lapinsky, A. E. Macias et al., "Critically ill patients with 2009 influenza $\mathrm{A}(\mathrm{H} 1 \mathrm{~N} 1)$ in Mexico," Journal of the American Medical Association, vol. 302, no. 17, pp. 1880-1887, 2009.

[6] S. A. R. Webb, V. Pettilä, I. Seppelt et al., "Critical care services and 2009 H1N1 influenza in Australia and New Zealand," New England Journal of Medicine, vol. 361, no. 20, pp. 1925-1934, 2009.

[7] S. Jain, L. Kamimoto, A. M. Bramley et al., "Hospitalized patients with $2009 \mathrm{H} 1 \mathrm{~N} 1$ influenza in the United States, AprilJune 2009," New England Journal of Medicine, vol. 361, no. 20, pp. 1935-1944, 2009.

[8] M. D. van Kerkhove, K. A. H. Vandemaele, V. Shinde et al., "Risk factors for severe outcomes following 2009 influenza a (H1N1) infection: a global pooled analysis," PLoS Medicine, vol. 8, no. 7, Article ID e1001053, 2011.

[9] S. A. Truelove, A. S. Chitnis, R. T. Heffernan, A. E. Karon, T. E. Haupt, and J. P. Davis, "Comparison of patients hospitalized with pandemic 2009 influenza A (H1N1) virus infection during the first two pandemic waves in Wisconsin," Journal of Infectious Diseases, vol. 203, no. 6, pp. 828-837, 2011.

[10] G. La Ruche, A. Tarantola, P. Barboza, L. Vaillant, J. Gueguen, and M. Gastellu-Etchegorry, "The 2009 pandemic H1N1 influenza and indigenous populations of the Americas and the Pacific," Euro Surveillance, vol. 14, no. 42, 2009.

[11] A. M. Presanis, R. G. Pebody, B. J. Paterson, B. D. Tom, and P. J. Birrell, "Changes in severity of 2009 pandemic A/H1N1 influenza in England: a Bayesian evidence synthesis," BMJ, vol. 343, Article ID d5408, 2011.

[12] S. Doshi, L. Kamimoto, L. Finelli, A. Perez, and A. Reingold, "Description of antiviral treatment among adults hospitalized 
with influenza before and during the 2009 pandemic: United States, 2005-2009," Journal of Infectious Diseases, vol. 204, no. 12, pp. 1848-1856, 2011.

[13] J. E. Hernandez, J. Graingera, L. Simonsen, P. Collisa, L. Edelmanc, and W. P. Sheridan "Impact of the 2009/2010 influenza A (H1N1) pandemic on trends in influenza hospitalization, diagnostic testing, and treatment," Influenza and Other Respiratory Viruses. In press.

[14] "Deaths related to 2009 pandemic influenza A, (H1N1) among American Indian/Alaska Natives-12 states," MMWR Morbidity and Mortality Weekly Report, vol. 58, pp. 1341-1344, 2009.

[15] D. L. Thompson, J. Jungk, E. Hancock, C. Smelser, and M. Landen, "Risk factors for 2009 pandemic influenza A, (H1N1)-related hospitalization and death among racial/ethnic groups in New Mexico," American Journal of Public Health, vol. 101, no. 9, pp. 1776-1784.

[16] G. Chowell, S. Echevarría-Zuno, C. Viboud, L. Simonsen, and M. A. Miller, "Epidemiological characteristics and underlying risk factors for mortality during the autumn 2009 pandemic wave in Mexico," PLoS One. In press.

[17] P. Santa-Olalla Peralta, M. Cortes Garcia, A. Limia Sanchez, J. Andres Prado, and I. Pachon Del Amo, "Critically ill patients with 2009 pandemic influenza A, (H1N1) infection in Spain: factors associated with death, April 2009-January 2010," Revista Española de Salud Pública, vol. 84, no. 5, pp. 547-567, 2010.

[18] R. Gilca, G. de Serres, N. Boulianne et al., "Risk factors for hospitalization and severe outcomes of 2009 pandemic H1N1 influenza in Quebec, Canada," Influenza and other Respiratory Viruses, vol. 5, no. 4, pp. 247-255, 2011.

[19] A. G. Randolph, F. Vaughn, R. Sullivan, L. Rubinson, and B. T. Thompson, "Critically ill children during the 2009-2010 influenza pandemic in the United States," Pediatrics, vol. 128, no. 6, pp. e1450-e1458, 2011.

[20] K. Wada, H. Nishiura, and A. Kawana, "An epidemiological analysis of severe cases of the influenza A (H1N1) 2009 virus infection in Japan," Influenza and other Respiratory Viruses, vol. 4, no. 4, pp. 179-186, 2010.

[21] R. T. C. Yokota, L. M. Skalinski, C. N. Igansi et al., "Risk factors for death from pandemic (H1N1) 2009, southern Brazil," Emerging Infectious Diseases, vol. 17, no. 8, pp. 1467-1471, 2011.

[22] J. C. Kwong, M. A. Campitelli, and L. C. Rosella, "Obesity and respiratory hospitalizations during influenza seasons in ontario, Canada: a cohort study," Clinical Infectious Diseases, vol. 53, no. 5, pp. 413-421, 2011.

[23] O. W. Morgan, A. Bramley, A. Fowlkes et al., "Morbid obesity as a risk factor for hospitalization and death due to 2009 pandemic influenza $\mathrm{A}(\mathrm{H} 1 \mathrm{~N} 1)$ disease," PloS one, vol. 5, no. 3, p. e9694, 2010.

[24] J. K. Louie, M. Acosta, M. C. Samuel et al., "A novel risk factor for a novel virus: obesity and 2009 pandemic influenza a (H1N1)," Clinical Infectious Diseases, vol. 52, no. 3, pp. 301$312,2011$.

[25] K. A. Ward, P. J. Spokes, and J. M. Mcanulty, "Case-control study of risk factors for hospitalization caused by pandemic (H1N1) 2009," Emerging Infectious Diseases, vol. 17, no. 8, pp. 1409-1416, 2011.

[26] D. J. Muscatello, M. Barr, S. V. Thackway, and C. Raina Macintyre, "Epidemiology of influenza-like illness during pandemic (H1N1) 2009, New South Wales, Australia," Emerging Infectious Diseases, vol. 17, no. 7, pp. 1240-1247, 2011.

[27] J. S. Nguyen-Van-Tam, P. J. M. Openshaw, A. Hashim et al., "Risk factors for hospitalisation and poor outcome with pandemic A/H1N1 influenza: United Kingdom first wave (May-September 2009)," Thorax, vol. 65, no. 7, pp. 645-651, 2010.

[28] T. Uyeki, "Antiviral treatment for patients hospitalized with 2009 pandemic influenza A (H1N1)," New England Journal of Medicine, vol. 361, no. 23, Article ID e110, 2009.

[29] Centers for Disease Control and Prevention, "Updated interim recommendations for the use of antiviral medications in the treatment and prevention of influenza for the 2009-2010 season," http://www.cdc.gov/h1n1flu/recommendations.htm, 2010.

[30] R. Gilca, G. de Serres, N. Boulianne et al., "Risk factors for hospitalization and severe outcomes of 2009 pandemic H1N1 influenza in Quebec, Canada," Influenza and other Respiratory Viruses, vol. 5, no. 4, pp. 247-255, 2011.

[31] A. L. H. Iglesias, K. Kudo, T. Manabe, A. E. C. Berdugo, and A. C. Baeza, "Reducing occurrence and severity of pneumonia due to pandemic H1N1 2009 by early oseltamivir administration: a retrospective study in Mexico," PLoS One, vol. 6, no. 7, Article ID e21838, 2011.

[32] W. Hanshaoworakul, J. M. Simmerman, U. Narueponjirakul et al., "Severe human influenza infections in Thailand: oseltamivir treatment and risk factors for fatal outcome," PLoS ONE, vol. 4, no. 6, Article ID e6051, 2009.

[33] N. Lee, K. W. Choi, P. K. S. Chan et al., "Outcomes of adults hospitalised with severe influenza," Thorax, vol. 65, no. 6, pp. 510-515, 2010.

[34] A. McGeer, K. A. Green, A. Plevneshi et al., "Antiviral therapy and outcomes of influenza requiring hospitalization in Ontario, Canada," Clinical Infectious Diseases, vol. 45, no. 12, pp. 1568-1575, 2007.

[35] A. Kumar, "Early versus late oseltamivir treatment in severely ill patients with 2009 pandemic influenza A (H1N1): speed is life," Journal of Antimicrobial Chemotherapy, vol. 66, no. 5, Article ID dkr090, pp. 959-963, 2011.

[36] G. Chowell, C. Viboud, L. Simonsen, M. Miller, and S. Echevarría-Zuno, "Impact of antiviral treatment and hospital admission delay on the risk of death of 2009 A/H1N1 pandemic influenza in Mexico, April-December 2009," BMC Infectious Diseases, vol. 12, p. 97, 2011. 


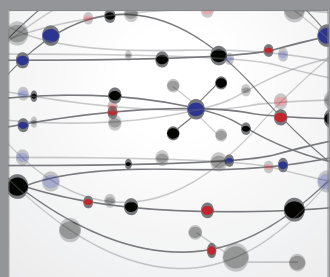

The Scientific World Journal
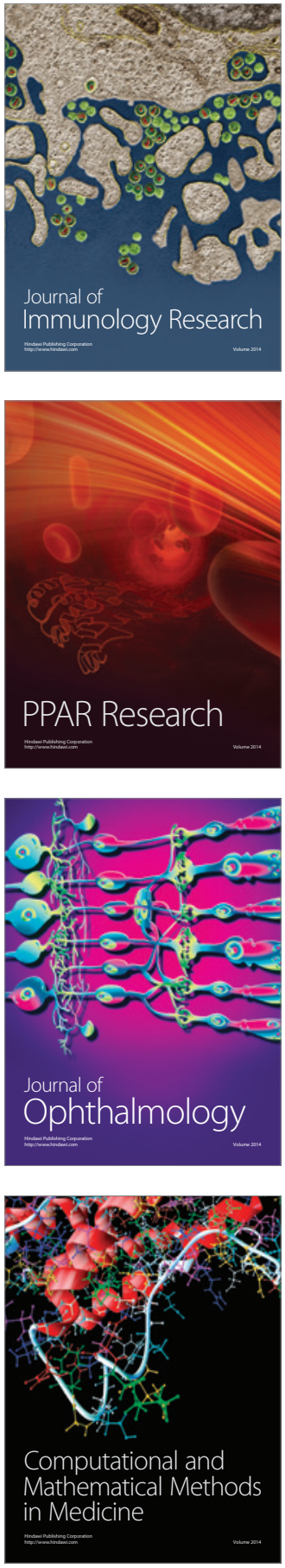

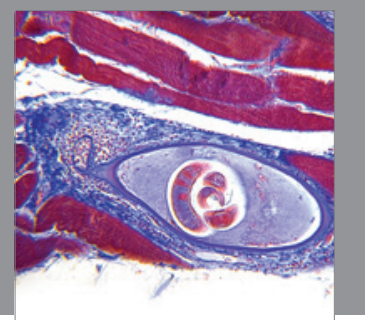

Gastroenterology

Research and Practice
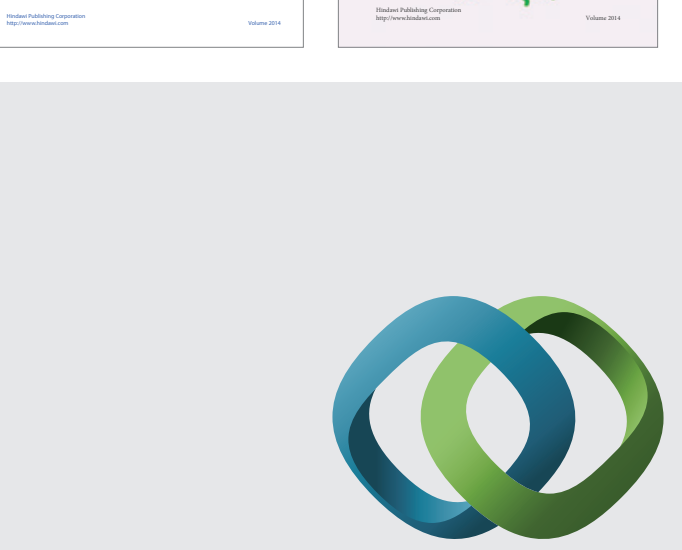

\section{Hindawi}

Submit your manuscripts at

http://www.hindawi.com
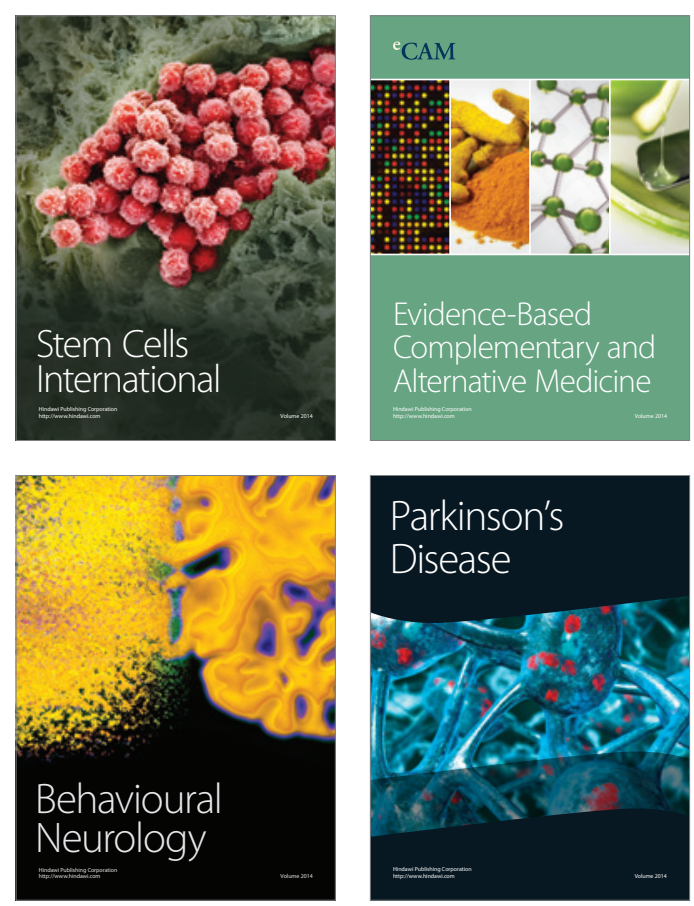

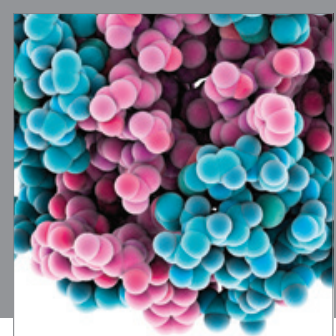

Journal of
Diabetes Research

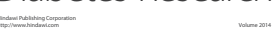

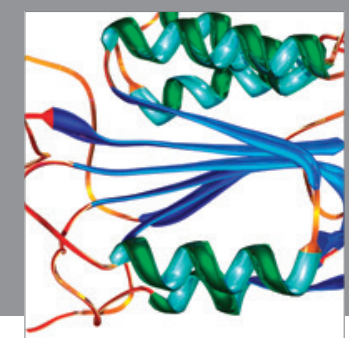

Disease Markers
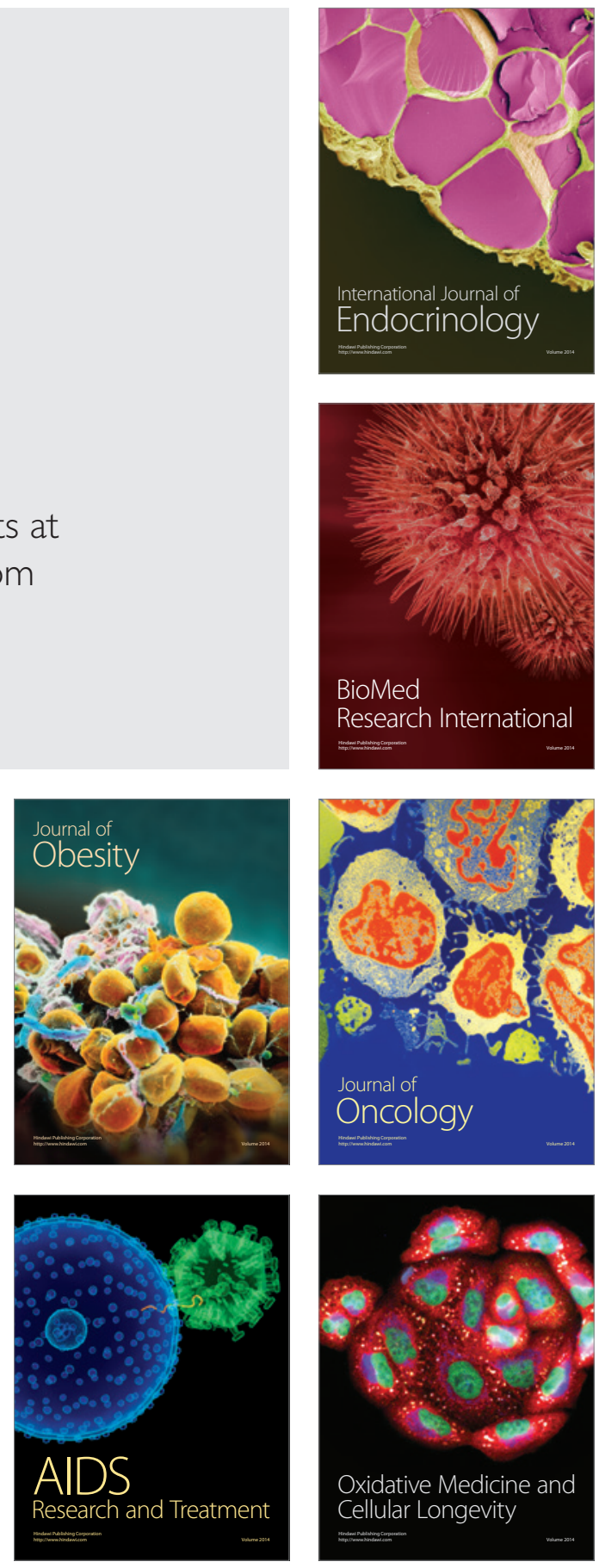